\title{
Research on Courses "Three Degrees" Construction of Electronic Information Specialty in Private Colleges and Universities
}

\author{
Ding Xue-yong ${ }^{1}$, Su Hong-rui ${ }^{2}$, Wang Yuan ${ }^{1}$, Wang Lian-sheng ${ }^{1}$ \\ ${ }^{1}$ The Polytechnic Institute, Sanya University, Sanya, China \\ ${ }^{2}$ The Foreign Languages Institute, Sanya University, Sanya, China
}

Email address:

ding2008ding@163.com (Ding Xue-yong),393024108@qq.com (Su Hong-rui), 93216402@qq.com (Wang Yuan), 116338596@qq.com (Wang Lian-sheng)

\section{To cite this article:}

Ding Xue-yong, Su Hong-rui, Wang Yuan, Wang Lian-sheng. Research on Courses "Three Degrees" Construction of Electronic Information Specialty in Private Colleges and Universities. International Journal of Elementary Education. Vol. 8, No. 3, 2019, pp. 68-73. doi: $10.11648 /$ j.ijeedu. 20190803.13

Received: September 1, 2019; Accepted: October 16, 2019; Published: October 23, 2019

\begin{abstract}
In order to respond positively to the demands of the times and internal demands, the school level actively encourages first try, batch construction, and quality control. The overall planning of the college level, the active participation of deans and department heads, the selection of teachers, and quality priority. From the aspects of strengthening the management of learning process, innovating practical teaching mode, strengthening the construction of teaching staff, reforming teaching methods and teaching means, this paper carries out the construction of saturation, depth and academic tension of core courses of electronic and Information Engineering Specialty in private colleges and universities. This is great strategic significance for continuously improving the quality of curriculum and comprehensively improving the ability of personnel training.
\end{abstract}

Keywords: Course Saturation, Course Depth, Academic Stress, Electronic and Information Engineering Specialty, "Three Degrees" Construction

\section{Introduction}

In June 2018, the Ministry of Education convened a national conference on undergraduate education in Colleges and universities in the new era. The conference emphasized that we should adhere to the principle of "taking this as the foundation", promote the "four returns", strengthen the construction of high-level undergraduate education, comprehensively improve the quality of personnel training, and bring up new people of the era who can be the major task of national rejuvenation [1]. At the same time, in order to effectively improve the quality of teaching, the Ministry of Education has made it clear that colleges and universities should comb the teaching content of each course comprehensively, eliminate "water course" and create "golden course", rationally enhance the academic challenge, increase the difficulty of the course and expand the depth of the course [2]. The phenomenon of "water course" in undergraduate education is widespread in Chinese universities, which is closely related to the curriculum design of four-year academic cycle and the teaching methods of teachers. Professional core curriculum is the basis of students' professional introduction. Professional teachers should make scientific allocation and reasonable teaching as a "learning", and improve the quality of curriculum together with the educational concept of "educational community". In order to train high-quality talents to meet the needs of the society, colleges and universities need to return from "strict entry and wide exit" to "strict entry and strict exit". This requires a comprehensive and systematic review of the whole process of talent cultivation in Institutions of higher learning. The premise of "strictness" is that the courses offered by colleges and universities are necessary, valuable and of high quality. In order to strengthen the course construction in an all-round way, we should first attach importance to the construction of the course system, and then strengthen the 
course construction. It is meaningful to build the "golden course" of "water course".

Because most of the students enrolled by private colleges and universities are poor in mathematic skills, low interest in learning, weak teachers and investment in laboratory funds, it is difficult for the trained talents to meet the requirements of industry development, the tradition of talent training mode, the lack of docking between curriculum and industry talent standards and requirements, and the teaching content and application. Lack of cohesion. Separation of practical teaching and theoretical teaching. Insufficient comprehensiveness and design of experimental courses. Single cultivation approach, teaching based on classroom knowledge imparting, lack of linkage with industry, insufficient practice in industry; poor autonomy of students' learning, lack of interest in students' learning, insufficient development of research-based learning, and inadequate ability of practical innovation not strong [3-4]. However, these students have strong practical ability, thinking ability and innovative ability. It is urgent to solve how to develop course saturation, depth and academic tension for students who are not good at learning but good at doing, especially for engineering majors who require higher mathematics foundation such as electronic information. This paper mainly elaborates on the measures and construction schemes for the "three-degree" construction of electronic and information engineering courses in private colleges and universities, with a view to finding a "three-degree" course which is suitable for the characteristics of students in private colleges and universities, conforms to the development concept of schools, can effectively improve the teaching quality of courses and comprehensively improve the quality of personnel training construction measures and plans.

\section{Principles of Courses "Three Degrees" Construction}

\subsection{Adhering to the Quality Core, "Early" and "New" First}

The core of the "three-degree" construction of curriculum is to improve the quality of curriculum. We should work hard on the quantity of information, the viewpoint of discipline, the theory and method of specialty. On the one hand, it is necessary to start "early" to achieve knowledge prophecy, benefit first from saturation, learn first from methods and experience first from application value; on the other hand, it is necessary to "new" to emphasize "new" under the condition of "systematic structure of professional knowledge", that is, "new ideas, new ideas, new contents, new methods and new technologies", with emphasis on "early". Learn and learn new, learn useful [5].

\subsection{Adhere to System Design and Management Synchronization}

In terms of teaching management arrangement, systematic actions are designed to systematically support the "three-dimensional" construction of curriculum, including the systematization of teaching and the systematization of teaching matching. The systemization of teaching takes curriculum syllabus as the carrier, and is designed by the relevant teachers according to the unified construction standard of the school. The systemization of teaching matching is designed by the school and arranged by the college. It is a "four-year academic jigsaw" with seamless cohesion of saturation, depth and tension for students [5].

\subsection{Adhere to "Add and Subtract" and Fine Stock}

In terms of course saturation, depth and academic arrangement tension, we should add up the credits of core courses. At the same time, we should also do "subtraction" to ensure that teachers and students can concentrate on the "three-degree" construction of the curriculum [5].

\section{Guiding Ideas and Objectives of Courses "Three Degrees" Construction}

In order to implement the spirit of the undergraduate education work conference of the Ministry of Education, actively respond to the changes in the internal environment of students' source structure, effectively implement the development strategy of students-centered schools, closely adhere to the goal of improving curriculum quality and continuously focus on curriculum construction, private colleges and universities should resolutely promote the "three-degree" construction of curriculum in order to enhance students' competition. Strength, promote the growth of students. Focusing on undergraduate education, focusing on "students' competitiveness" and focusing on the "three-dimensional" construction of curriculum is an important measure to implement the unified requirements of the Ministry of Education for improving the quality of curriculum in colleges and universities. It is also a rapid response of schools to the changes in the structure of new students [5].

Although electronic information and communication technology has developed rapidly, the basic theory and knowledge of communication have not changed much. Therefore, the teaching system of basic courses and professional basic courses is basically unchanged, but the teaching contents and methods need to be adjusted. The "three-degree" construction of the curriculum focuses on the specialized courses (specialized orientation courses and specialized elective courses) and practical teaching links (teaching conditions). Maintain the existing talent training program, professional curriculum system structure unchanged, focusing on the core curriculum "three-dimensional" construction. The core courses are selected from the basic courses and core courses of disciplines in the existing talent training programs, and the core professional knowledge and ability are constructed 
according to the characteristics of disciplines. In the course of "three degrees" construction, special attention should be paid to arousing students' confidence in curriculum quality and academic self-confidence so as to further gain competitive advantage with peer groups [5].

\section{Measures and Programmes of Courses "Three Degrees" Construction}

To carry out the "three-degree" construction of electronic and information engineering courses in private colleges and universities and improve the quality of personnel training in an all-round way, the most important thing is to strengthen the management of the learning process, sort out the teaching contents of the courses offered, pay attention to the relevance between the courses before and after, streamline the teaching contents, make full use of network resources and use of information platform. Attract students' attention, arouse students' learning mood, activate classroom atmosphere, improve students' heart rate, improve teaching quality, rationally enhance academic challenges, increase curriculum difficulty and expand curriculum depth. At the school level, we should actively encourage and support the "three-degree" construction of professional courses. Leading cadres at the college level should take the lead in carrying out the "three-degree" construction of professional courses to stimulate the enthusiasm of teachers. We should strengthen the assessment of learning process, make full use of MOOC network resources of Chinese universities, reform teaching methods, teaching means and assessment methods, improve the saturation and depth of curriculum learning, enhance students' learning tension, strictly control the exit of graduation and resolutely cancel it by means of rain classroom or micro-assistant teaching platform. The "Qingkao" system [2].

\subsection{Encouraging Activeness at School Level, First Try, Batch Construction and Quality Control}

At the school level, colleges should be selected as pilot projects. Each college recommends specialties to participate in the construction, and each specialty selects 6-8 core courses for the construction. And in the form of setting up projects to give research funds for curriculum construction, in the calculation of teaching workload to support supporting. In the course of "three degrees" construction, the responsibility system of the principal person in charge is implemented, and the responsibility implementation system of the whole system is formed step by step. Teaching quality control department, teachers department, student center and other departments also actively cooperate to vigorously promote the "three-dimensional" construction. Through a series of school policies and measures, teachers can realize the importance of the "three-dimensional" curriculum construction, improve the enthusiasm of participating in the construction, through quality control, also let the teachers involved in the "three-dimensional" curriculum construction feel the pressure of the task.

\subsection{College-level Overall Planning, Participation of Deans and Department Directors, Selection of Teachers, Priority of Quality}

Each college should set up a "three-dimensional" curriculum construction promotion team, which is responsible for the overall planning, progress control and supervision of the use of funds for the "three-dimensional" curriculum construction. Establish an effective quality monitoring system of "three-degree" curriculum construction, which covers teachers' teaching and students' learning process comprehensively, pays attention to the follow-up evaluation of students' learning effect, carries out curriculum construction evaluation regularly, pays attention to teaching feedback, carries out regular student discussions and understands students' needs. The deans and department directors of each college should take part in the "three-dimensional" construction of at least one course, play a leading role in the course construction, and the quality of the "three-dimensional" construction of the course should be excellent.

\subsection{Strengthen the Management of Learning Process and Build "Three Degrees" of the Core Course of Electronic Information Engineering Specialty}

In accordance with the requirements of national professional certification (Washington Agreement, etc.) and the National Standard for Teaching Quality of Undergraduate Specialty in General Colleges and Universities, a new talent training program has been revised; a reform of the training mode of "quasi-professional" applied talents has been actively explored. Curriculum construction has been strengthened; teaching contents and methods have been reformed, and efforts have been made to improve them. Course saturation and gold content; to improve "graduate entrance examination rate, graduate study abroad rate, employment rate and employment quality" as a starting point promote the construction of style of study as a whole, guide students to change their learning concepts and methods, create a good learning environment and culture. Strengthen the construction of teaching style, strengthen the training of teachers, No. Continuously improve teachers' teaching and academic research ability, strengthen the construction of teaching facilities, and provide students with good learning conditions and environment [5].

In the current talent training program, the "three-degree" construction of curriculum should only do "stock" instead of "increment" or "reduction" [5]. Classroom teaching should be reasonable "adding code" and "adding burden" to students. The focus of undergraduate education is what students learn in school, what they will use in the future, and what they can use for sustainable development. The construction of classroom quality is an important grasp, grasping the core curriculum will basically grasp the professional quality. Emphasize the integration of professional knowledge, 
increase the capacity of knowledge, deepen the theory while teaching students the application of knowledge, add cases, deepen the integration of curriculum content, highlight the timeliness and effectiveness of knowledge, so that students can apply what they learn.

\subsubsection{Optimizing and Adjusting the Teaching Plan of Specialty, Designing Scientifically and Innovating the Practical Teaching Mode Boldly}

Although the students of ordinary private colleges have poor theoretical learning ability, they have strong practical desire and ability. Combining with the actual situation and characteristics of private colleges and universities, we should establish training effective and practical innovative talents as our training goal and school-running orientation, and strengthen practical teaching. According to the requirements of electronic information in the National Standard for Teaching Quality of Undergraduate Specialty in Universities and Colleges, the professional teaching plan needs to be carefully revised and optimized through industry investigation. In the new teaching plan, we should strengthen the foundation, emphasize application, respect personality, pay attention to practice and innovation, and form a teaching system with the core of cultivating students' innovative consciousness and practical ability.

The guiding ideology of adjusting and optimizing professional teaching plan should fully embody the orientation and goal of professional training. This paper mainly carries on the adjustment and optimization from the following aspects: 1) the teaching plan should accurately grasp the training orientation of applied and practical undergraduate talents; 2) the teaching plan should clarify the three characteristics of applied talents training, namely, the high level of theory, the diversity of applied skills and abilities; 3 ) the teaching plan should adhere to four principles, namely The principles of specialty construction of "science, standardization and broadening", "sufficient theory, practice as the most important" teaching principle, "broad foundation, ability, innovation" personnel training principle and the principle of promoting students"' happy learning, independent growth" education principle. (4) The teaching plan should be based on the demand for talents in the economic and social development. The teaching plan should improve the three-semester model, especially the practical teaching plan of summer semester should be scientific, standardized and feasible [6-7].

\subsubsection{Optimizing the Teaching Management System, Strengthening the Construction of Teachers and Improving Young Teachers' Practical and Innovative Ability}

Teachers are the foundation of improving teaching quality. On the one hand, we should actively introduce experimental teaching and management personnel with high professional quality, and on the other hand, we should train the existing teaching staff. Firstly, we should optimize the teaching management system and set up a curriculum team (group). The core of the teaching team is a series of courses, especially the main courses. The curriculum module is constructed according to the curriculum category, and the teaching team is constructed by the curriculum module. When setting up teaching team and course echelon, young teachers are consciously brought into each teaching team and course echelon. Under the guidance of experienced old teachers, they are required to positioning their teaching direction carefully, teach 1-2 main basic courses well, and get exercise and improvement in teaching practice. It is necessary to sort out the teaching contents of each course in an all-round way, eliminate the "water course" and create the "golden course".

In order to cultivate teachers' practical ability, teachers, especially young teachers, should be encouraged to enter the laboratory regularly, organize and arrange teachers to participate in the training of various competitions, and periodically, through the system of teachers' responsibility for experimental courses, the establishment of funds for practical teaching research projects and the improvement of laboratory research conditions. Teachers should be sent out to participate in various kinds of special training to encourage them to update their knowledge and carry out scientific research.

\subsubsection{Selection and Compilation of Textbooks Suitable for Our Students}

In the selection of textbooks, it is necessary to carefully select textbooks according to the direction of professional development, the requirements of professional teaching plan and curriculum content, and the compilation, evaluation and selection system of textbooks. At the same time, according to the characteristics of the rapid development of electronic information and communication technology, attention should be paid to the selection of new professional textbooks to ensure that students can access to the latest relevant professional knowledge as soon as possible, and expand students' reading. While actively choosing excellent national textbooks, teachers are encouraged and organized to actively compile series of textbooks suitable for this professional course according to the specific situation of students.

\subsubsection{Diversification of Teaching Methods, Modernization of Teaching Means, Cultivation of Students' Self-study Ability and Innovative Ability}

Pay attention to the reform of teaching methods and means, and gradually realize the best combination of multimedia teaching and conventional blackboard teaching according to the characteristics of different courses, so as to achieve better teaching effect. Efforts should be made to diversify teaching methods, modernize teaching means, focus on classroom teaching design, increase students' participation, stimulate students' interest in learning, and ensure the cultivation of students' basic vocational ability and innovative ability.

1) Actively promote two-way and interactive teaching mode, adopt heuristic, lecture and discussion teaching methods, make full use of teaching tools such as rain classes, micro-assistants and Chinese MOOC network learning resources, to mobilize students' learning enthusiasm, 
initiative and creativity;

2) Circuit case teaching method is adopted to reflect the requirement of ability and knowledge in the course, so that students can get systematic training in basic skills.

3) Advocate the combination of multimedia courseware teaching and traditional teaching methods. Teachers should compile paper-based teaching plans, design blackboard books in the course of class, and also make multimedia courseware to reflect the scientific, advanced and interesting content of teaching, attract students' attention, improve their interest in learning and make students understand better. And master the knowledge and skills learned [8-9].

\subsubsection{Effectively Developing Discipline Competition and Promoting the Improvement of Students' Practical Innovation Ability}

Discipline competition is a process of deep understanding, systematic arrangement and practical application of knowledge. The results of the competition embodies students' ability to understand and use knowledge, physical quality, psychological quality and cooperative spirit. Participation in subject competitions can enable students to apply their theoretical knowledge to practice and cultivate their ability to solve practical problems and innovate. We should take the discipline and professional competition as the leading factor, promote the improvement of students' practical and innovative ability, and improve their comprehensive quality [10].

The institute should vigorously publicize the discipline competition, fully mobilize the enthusiasm of students to participate in the competition, encourage students to take part in China's "Internet +" College Students' innovation and entrepreneurship competition, the national "Challenge Cup" extracurricular scientific and technological work competition, the National Undergraduate Electronic Design Contest, and the national university student mathematics building, etc. It will be carried out to cultivate students' practical and innovative application ability and promote teaching reform and the improvement of teaching quality.

\subsubsection{Strengthen the Assessment of the Learning Process, Strictly Enforce the Examination Discipline, Resolutely Abolish the "Clearance Examination" System, and Increase Students' Tension}

The methods and contents of the assessment should embody the spirit of strict requirements and be conducive to checking the effects of teaching and learning. The comprehensive ability of students to master basic knowledge, analyze problems and solve problems should be assessed. Specific assessment methods can take the form of procedural assessment and diversified assessment according to the nature and characteristics of the course. Increase the proportion of process assessment scores in the total course scores [9]. Strict examination discipline, do a good job in the education and publicity of teachers and students' examination style and discipline, earnestly study the school's relevant provisions on examination, and ensure the effective implementation of the provisions. As for the phenomenon that invigilators do not conscientiously perform their invigilatory duties, once found, they report it immediately, once implemented, they should be dealt with seriously. Once students' violation of discipline and cheating are verified, they should be dealt with promptly according to the facts of students' violation of discipline and cheating according to the school regulations. Strictly control the exit of graduates, resolutely abolish the "clearance examination system", so that students become nervous about the examination and attach importance to learning.

For the core courses of electronic and information engineering, on the basis of classroom teaching and MOOC network resources teaching in Chinese universities, the saturation of students' learning is enhanced by setting up classroom exercises, assigning a large number of assignments and unit tests with the help of micro-assistant teaching platform. At the same time, the basic knowledge is taught in the course. At the same time, through the comprehensive use of MOOC network resources of Chinese universities, the test questions of this course and some of the postgraduate entrance examination questions of universities, the simple wireless communication equipment is designed selectively to enhance the depth of learning of the course; on the basis of enhancing students' learning saturation and learning depth, the course is done through the micro-assistant teaching platform. Limited test time, rejection of homework plagiarism, cancellation of final exam system for a certain number of late absences, full knowledge coverage system for final exams, high requirement system for final exams and pole system for school degree requirements can improve students' learning tension.

\section{Conclusion}

The "three degrees" construction docks the achievements of a series of teaching reforms in schools. It has the characteristics of different disciplines. Saturation, tension and depth are interrelated. They are related to students' cognitive habits, but also because of curriculum. At the school level, pilot projects must be carried out first, policy encouragement and financial support should be provided, and the leadership at the college level should take the lead, select the best ones and finally spread them out in an all-round way. "Good teachers" should find the best combination point between teachers and students, let students contact the frontier and professional knowledge as much as possible, form curricular thinking, feel pressure without pain, learn instead of burden, and establish a long-term learning mechanism.

Not only for the electronic information specialty of private colleges and universities, the course construction needs to be "three degrees", but also for other specialties and other disciplines, we should pay attention to the quality of the course construction, change the traditional way of University education, and improve the competitiveness of students. We should always keep in mind the purpose of "talent cultivation as the foundation" and the mission of running a school. At a 
new historical starting point, we should reform, innovate and forge ahead, and strive to run a good university with national confidence, social recognition, people's satisfaction and students' responsibility.

\section{Acknowledgements}

This work is supported by the provincial educational reform project funds of Hainan (Hnjg2019ZD-23).

\section{References}

[1] Ministry of Education of the People's Republic of China. Notice on Implementing the Spirit of the National Conference on Undergraduate Education in Colleges and Universities in the New Era [EB/OL]. (2018-08-27) (Information index: 360A08-07-2018-0016-1).

http://www.moe.gov.cn/srcsite/A08/.

[2] Ministry of Education of the People's Republic of China. Overall Rectification of Undergraduate Education: Eliminating "Water Course" and Strictly Keeping Graduation Pass. China Business Daily. 2018. 9.

[3] Lin Zhi-kan, Zhao-Feng, Zhang Zhi-wei. The Exploration about the Training Mode for Innovation and Entrepreneurial Talents for Electronic Information Major Students in Local Universities: Current situation, Problems and Prospects [J]. Higher Education Forum, 2016 (1): 30-35.
[4] Lin Zhi-kan. Retrospective Study and Consideration on Undergraduate Enterprise Education in Colleges [J]. Journal of Chongqing University of Technology (Social Science), 2014 (2): 116-122.

[5] San Ya university. Promoting Program of "Three Degrees" Construction of Courses [EB/OL]. (2019-01-19) [2018-12-30]. http://10.10.20.56:88/zfoa/runflow.do.

[6] Gu Tian-long, Jing Xin-xing, Guo Qing, Wei Yin-xia. A Research on the Training Mode Reform of College Engineering Practical Talents [J]. Research on Higher Education in China, 2012 (1): 107-110.

[7] Fang Hong, Lei Lin, Li Hong-lian, LUO Jun-yi. Practice of Training Mode for Electronic Information Innovative Project Application-Oriented Personnel [J]. Research and exploration in laboratory, 2013 (11): 308-310.

[8] Guo Ye-cai, Wang You-bao. Taking the Cooperative Construction of Electronic Information Specialty as an Opportunity to Construct the Training Mode of Talents by Classification-A Case Study of Nanjing University of Information Engineering [J]. University Education, 2014 (2): 54.

[9] Ding Xue-yong. Teaching Reform of Communication Principles and "3+3" Practical Teaching Mode [J], Electronic world, 2013 (16): 161.

[10] Huang Yu-xin, Zheng Hong-qing. Electronic Information Teaching Reform Based on Discipline Competition Incentive Method [J], 2019 (7): 146-151. 